\title{
Corrado Bologna, Le retour des dieux anciens: Giulio Camillo et Fontainebleau
}

\section{Filippo Fonio}

\section{(2) OpenEdition}

1 Journals

\section{Edizione digitale}

URL: https://journals.openedition.org/studifrancesi/40446

DOI: $10.4000 /$ studifrancesi.40446

ISSN: 2421-5856

Editore

Rosenberg \& Sellier

\section{Edizione cartacea}

Data di pubblicazione: 1 juillet 2004

Paginazione: 170

ISSN: 0039-2944

\section{Notizia bibliografica digitale}

Filippo Fonio, «Corrado Bologna, Le retour des dieux anciens: Giulio Camillo et Fontainebleau», Studi

Francesi [Online], 142 (XLVIII | I) | 2004, online dal 30 novembre 2015, consultato il 09 septembre 2021. URL: http://journals.openedition.org/studifrancesi/40446; DOI: https://doi.org/10.4000/studifrancesi. 40446

Questo documento è stato generato automaticamente il 9 septembre 2021.

\section{(c)}

Studi Francesi è distribuita con Licenza Creative Commons Attribuzione - Non commerciale - Non opere derivate 4.0 Internazionale. 


\title{
Corrado Bologna, Le retour des dieux anciens: Giulio Camillo et Fontainebleau
}

\author{
Filippo Fonio
}

\section{NOTIZIA}

CORRADO BOLOGNA, Le retour des dieux anciens: Giulio Camillo et Fontainebleau, in AA. VV., Poèsie italienne de la Renaissance, «Italique», 5 (2002), pp. 111-138.

Si tratta del testo di una Lezione Barbier-Mueller, tenuta presso l'Università di Ginevra il 5 dicembre 2001, in cui l'autore fa il punto delle ricerche finora condotte sulla figura dell'intellettuale Giulio Camillo, di formazione veneziana; tali ricerche hanno tra l'altro portato lo studioso al rinvenimento del manoscritto di Manchester, contenente le opere di Camillo. Il saggio in questione è incentrato sull'apporto della riflessione estetica di Camillo, e delle implicazioni del celebre teatro della memoria (su cui cfr. in part. Frances A. YATES, The Art of Memory, London, Routledge, 1966, capp. VI e VII), sulle decorazioni della Galleria del castello di Fontainebleau. Più in generale, lo studio consta di «réflexions sur le rapport au cours des premières années du XVI ème siècle entre littérature, mythographie, arts visuels, mnémotechniques, ésotérisme» (p. 112). Bologna fa notare come les dieux anciens tornino a Fontainebleau, parla di «retour de l'Esprit Classique» (p. 111), di imperium dell'uomo sugli dei, di «art de la Présence comme Absence récupérée dans les formes» (p. 112). Mettendo in evidenza la connessione tra retorica e raffigurazioni iconografiche, proponendo anzi una retorica iconica, lo studioso delinea i caratteri del sodalizio francese di pittori ed eruditi italiani, mitografi, cabalisti, ricostruendo il milieu in cui Luigi Alamanni, Francesco Zorzi, Giulio Camillo, Jacopo Corbinelli tra gli altri diedero vita a una proficua collaborazione. «À Fontainebleau se greffent [...] les expériences, les tecniques et les idéologies artistiques du manierisme italien le plus sophistiqué» (p. 118). Il castello di Fontainebleau, e l'impianto concettuale di stucchi e freschi che ne ornano le sale, rappresenta dunque una summa dell'harmonia mundi, paragonabile a quella realizzata da Camillo con il teatro della memoria nei confronti dello scibile umano. L'ultima parte del saggio si presenta 
sotto forma di una visita-lettura a questo palazzo-testo, le cui decorazioni si articolano in piani e stanze caratterizzate da innumerevoli richiami e corrispondenze. 